\title{
UVB radiation represses CYLD expression in melanocytes
}

\author{
SILKE KUPHAL ${ }^{1}$, NADJA SCHNEIDER ${ }^{1}$, RAMIN MASSOUMI ${ }^{2}$, \\ CLAUS HELLERBRAND ${ }^{1}$ and ANJA KATRIN BOSSERHOFF ${ }^{1}$
}

\author{
${ }^{1}$ Emil-Fischer-Center, Institute of Biochemistry, Friedrich Alexander University Erlangen-Nuremberg, D-91054 Erlangen, \\ Germany; ${ }^{2}$ Department of Laboratory Medicine, Translational Cancer Research, Lund University, SE-221 00 Lund, Sweden
}

Received March 15, 2017; Accepted June 21, 2017

DOI: $10.3892 / \mathrm{ol} .2017 .7120$

\begin{abstract}
CYLD lysine 63 deubiquitinase (CYLD) was originally identified as a tumor suppressor that is mutated in familial cylindromatosis. Unlike in cylindromatosis, downregulation of the deubiquitinase CYLD in melanoma, a highly aggressive tumor, is not caused by mutations in the $C Y L D$ gene, but rather by a constitutive and high expression of the snail family transcriptional repressor 1 (SNAIL1). A reduced CYLD level leads to B-cell lymphoma-3/p50/p52-dependent nuclear factor $-\kappa \mathrm{B}$ activation, which in turn triggers the expression of genes such as cyclin D1 and N-cadherin. Elevated levels of cyclin D1 and $\mathrm{N}$-cadherin promote melanoma proliferation and invasion. By analyzing the regulation of CYLD expression in melanocytes, the present study identified a signaling pathway that is regulated in response to ultraviolet $B$ (UVB) radiation in melanocytes. UVB light leads to an extracellular signal-regulated kinase-mediated induction of SNAIL1 and subsequent downregulation of $C Y L D$ expression in normal human epithelial melanocytes. The UVB-mediated suppression of CYLD in melanocytes may have a key role in the reaction to UV stimuli, and may also potentially be involved in the early malignant transformation processes.
\end{abstract}

\section{Introduction}

Cutaneous melanoma is a heterogeneous disease affecting the regulation of multiple genes and proteins that contribute to the strong proliferation and invasion of degenerated melanocytes into the dermis and subsequent metastatic dissemination of melanoma cells and progression of the disease (1).

Ultraviolet (UV) light exposure is considered an important predisposing factor that triggers continuous proliferation

Correspondence to: Dr Silke Kuphal, Emil-Fischer-Center, Institute of Biochemistry, Friedrich Alexander University Erlangen-Nuremberg, Fahrstrasse 17, D-91054 Erlangen, Germany E-mail: silke.kuphal@fau.de

Abbreviations: UVB, ultraviolet B; SNAIL1, snail family transcriptional repressor 1; NHEMs, normal human epidermal melanocytes; ERK, extracellular signal-regulated kinase

Key words: UVB, melanocytes, CYLD, SNAIL1, ERK of certain melanocytes, which do not undergo senescence, and therefore support the development of melanoma (2). In melanocytes, UV light usually induces pigmentation. In this case, proliferation and pigment production is stimulated by UV-induced DNA damage to keratinocytes, which subsequently secrete $\alpha$-melanocyte stimulating hormone ( $\alpha \mathrm{MSH})(3) . \alpha \mathrm{MSH}$ binds to the melanocortin 1 receptor, which is expressed on melanocytes (4). Additional research demonstrated that UVB-induced DNA lesions also cause genetic mutations directly in melanocytes, with $\mathrm{C} \rightarrow \mathrm{T}$ transitions at dipyrimidine sites (5).

However, recent findings revealed that the photo-carcinogenesis pathway is more complex, with consequences in which each of these processes, mediated by various cellular, biochemical and molecular changes, are closely associated with each other (6).

Although UVA is the most prevalent component of solar UV radiation reaching the surface of the Earth, it mainly causes skin photo-aging (solar elastosis), but it is less carcinogenic compared to UVB radiation (7). By contrast, although UVB radiation only constitutes a minor part of solar radiation, it is carcinogenic at significantly lower doses compared with UVA radiation. UVB has a direct mutagenic effect on DNA as it is maximally absorbed by this primary chromophore (8). UV photon energy absorption by DNA decreases constantly at longer wavelengths (in the UVA range); therefore, UVB radiation is considered the major cause of skin cancer $(9,10)$. Notably, Noonan et al (11) reported that only a single dose of burning $\mathrm{UV}$ radiation to neonate hepatocyte growth factor/scatter factor-transgenic mice is necessary and sufficient to induce melanoma with a high incidence. Although supported by several studies, the molecular mechanism of melanoma induction by UV irradiation is not fully understood $(12,13)$.

Cyld was first identified as a gene associated with familial cylindromatosis, a disease showing multiple benign skin tumors that result from $C y l d$ germline mutations (usually nonsense or missense mutations) associated with somatic mutations in dermal cells (loss of heterozygosity) (14). In previous studies, the expression and function of CYLD in malignant melanoma and basal cell carcinoma has been analyzed $(15,16)$. These uncovered a new mechanism, revealing that the zinc-finger transcription factor SNAIL1 drives melanoma cells to a mitogenic and metastatic phenotype via downregulating the expression of CYLD. Loss of CYLD paves the way for activation of p50/p52 subunits of nuclear factor- $\kappa \mathrm{B}(\mathrm{NF}-\kappa \mathrm{B})$, 
resulting in stimulation of the expression of genes, including cyclin D1 and $\mathrm{N}$-cadherin expression. The induced target genes consequently lead to enhanced proliferation, migration and invasiveness of melanoma cells in vitro, as well as tumor growth and metastasis in vivo. Notably, increased SNAIL1 expression and reduced CYLD levels are inversely correlated with progression-free and overall survival of melanoma patients (16). Thus, it was shown that SNAIL1 has an important role in melanoma progression (17) and that one of the molecular mechanisms involved is the downregulation of CYLD. However, the role of SNAIL1 and CYLD in melanocyte proliferation and migration, as well as early malignant transformation, remains elusive.

In the present study, the effect of UVB radiation, one of the major promoting factors for the development of skin cancer, on SNAIL1 expression was investigated. Induced signaling via the ERK-SNAIL1 axis in normal primary human melanocytes, which reduces CYLD expression in UVB dependency, was identified.

\section{Materials and methods}

Cells and cell culture. The melanoma cell line Mel Ei was derived from a primary cutaneous melanoma, and the melanoma cell line Mel Im was isolated from metastasis. These cell lines were provided by Professor Judith P. Johnson (Cancer Immunology, Ludwig-Maximilians University, Munich, Germany) (18). The cell lines were cultured in Dulbecco's modified Eagle's medium, supplemented with penicillin (400 U/ml), streptomycin $(50 \mu \mathrm{g} / \mathrm{ml})$ and $10 \%$ fetal calf serum (all Sigma-Aldrich; Merck KGaA, Darmstadt, Germany). Primary normal human epidermal melanocytes (NHEMs) were isolated and cultured as described in a previous study $(18,19)$. Melanocytes were cultivated in M2 medium (PromoCell GmbH, Heidelberg, Germany). All cell lines were incubated at $37^{\circ} \mathrm{C}$ in an $8 \% \mathrm{CO}_{2}$ humidified atmosphere.

NHEMs were treated with the chemical mitogen-activated protein (MAP) kinase inhibitors PD98059 and UO126 [specific for MAP kinase kinase (MEK) 1 and MEK2; both Calbiochem; Merck KGaA, Darmstadt, Germany] for $6 \mathrm{~h}$. Control cells were incubated with the vehicle dimethyl sulfoxide alone.

$U V B$ radiation. UVB radiation of NHEMs seeded in $\mathrm{M} 2$ medium (PromoCell, Heidelberg, Germany) without PMA was performed with defined UVB doses (Whatman Biometra Transilluminator; Biometra GmbH, Göttingen, Germany). Kinase inhibitors were added before UVB radiation at a concentration of $20 \mu \mathrm{M}$, and due to their light sensitivity, renewed immediately after radiation in fresh medium at a concentration of $10 \mu \mathrm{M}$. For quenching of singlet oxygen, cells were treated with histidine (50 $\mathrm{mM}$ in PBS) $1 \mathrm{~h}$ prior to and during UVB administration $\left(80 \mathrm{~mJ} / \mathrm{cm}^{2}\right)$. The irradiated cells were maintained at $37^{\circ} \mathrm{C}$ in a $5 \% \mathrm{CO}_{2}$ atmosphere for $3 \mathrm{~h}(\mathrm{Mel}$ Ei cells) and 5 h (NHEMs).

Expression analysis. Isolation of total cellular RNA from the Mel Ei, Mel Im cell lines and primary NHEM was performed using the E.Z.N.A. MicroElute Total RNA kit (Omega Bio-Tek, VWR Darmstadt, Germany) according to the manufacturer's protocol. RNA concentration was measured with a NanoDrop
Table I. Primer sequences for expression analysis of cyclin D1, CYLD, N-cadherin, SNAIL and $\beta$-actin.

\begin{tabular}{ll}
\hline Gene & \multicolumn{1}{c}{ Primer sequence } \\
\hline Cyclin D1 & F: 5'-GCCTGTGATGCTGGGCACTTCATC-3' \\
& R: 5'-TTTGGTTCGGCAGCTTGCTAGGTG-3' \\
CYLD & F: 5'-TGCCTTCCAACTCTCGTCTTG-3' \\
& R: 5'-AATCCGCTCTTCCCAGTAGG-3' \\
N-cadherin & F: 5'-TGGATGAAGATGGCATGG-3' \\
& R: 5'-AGGTGGCCACTGTGCTTAC-3' \\
SNAIL & F: 5'-AGGCCCTGGCTGCTACAAG-3' \\
& R: 5-ACATCTGAGTGGGTCTGGAG-3' \\
$\beta$-actin & F: 5-CTACGTCGCCCTGGACTTCGAGC-3' \\
& R: 5'-GATGGAGCCGCCGATCCACACGG-3'
\end{tabular}

CYLD, CYLD lysine 63 deubiquitinase; N-cadherin, Neural cadherin; SNAIL, snail family transcriptional repressor 1; F, forward; $\mathrm{R}$, reverse.

spectrophotometer (NanoDrop Technologies; Thermo Fisher Scientific, Inc., Wilmington, DE, USA) and cDNA was generated by reverse transcription using the Super Script II Reverse Transcriptase kit (Thermo Fisher Scientific. Inc., Waltham, MA, USA), with each reaction containing $500 \mathrm{ng}$ of total RNA according to the protocol of the manufacturer. Analysis of mRNA expression was performed using quantitative Real-Time PCR on the LightCycler 480 system (Roche Diagnostics GmbH, Mannheim, Germany). A volume of $1 \mu \mathrm{l}$ cDNA template, $0.5 \mu \mathrm{l}$ of forward and reverse primers (each $20 \mu \mathrm{M}$ ) and $10 \mu \mathrm{l}$ of SYBR Green I (Roche Diagnostics $\mathrm{GmbH}$ ) were combined to a total volume of $20 \mu \mathrm{l}$. Specific primers for CYLD, cyclin D1, $\mathrm{N}$-cadherin and SNAIL1 expression analysis are summarized in Table I. The housekeeping gene was $\beta$-actin (Table I).

Protein analysis. Protein extraction, analysis and western blotting were performed as previously described (20), applying the following primary antibodies: Polyclonal anti-CYLD [cat. no. 4495; dilution, 1:1,000; Cell Signaling Technology, Inc., Danvers, MA, USA; (21)], anti-p44/42 MAP kinase (cat. no. 9102; dilution, 1:1,000) or anti-phospho-p44/42 MAP kinase (cat. no. 4370; dilution, 1:1,000; both Cell Signaling Technology, Inc.) and anti- $\beta$-actin (cat. no. A5441; dilution, 1:5,000; Sigma-Aldrich; Merck KGaA).

Transfection/transduction of cell lines. To express p65 and an

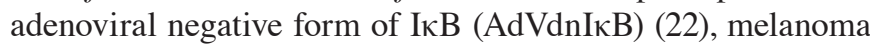
cells were transiently transfected or transduced with the expression plasmid or adenovirus, respectively as previously described (23).

Statistical analysis. All experiments were performed on at least 3 independent occasions. Results are presented as the mean \pm standard error of the mean (SEM). Comparison between groups was made using a one-way analysis of variance followed by a Kruskal-Wallis test, and comparisons between CYLD expression in NHEM cells with and without UVB 
A

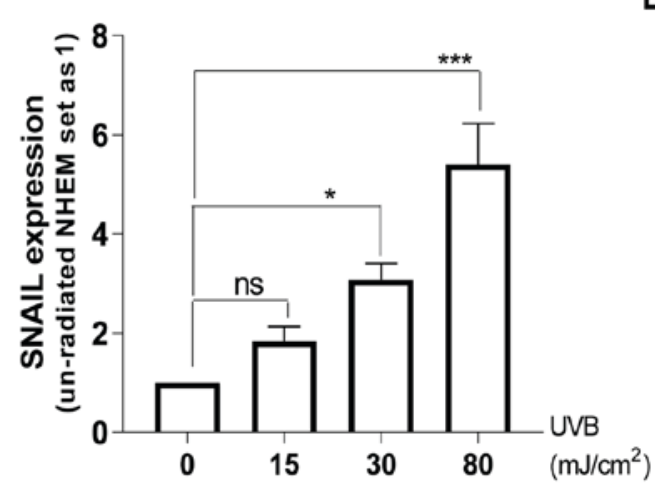

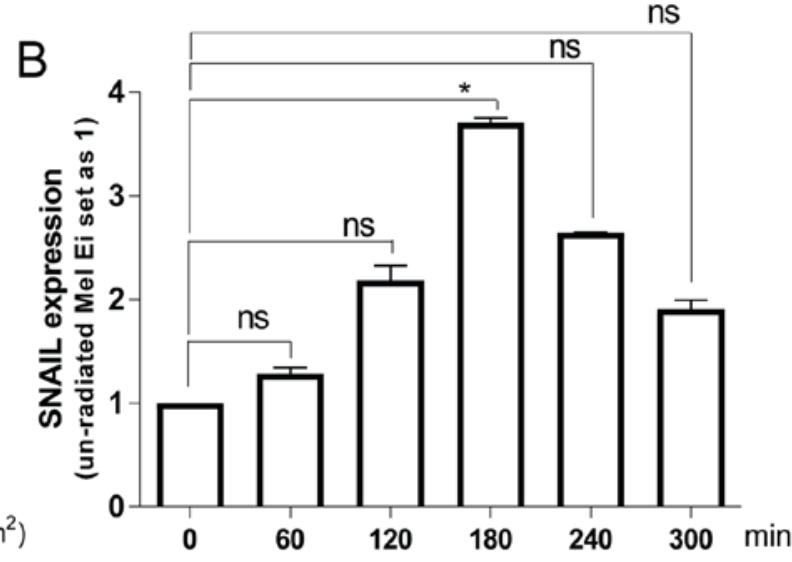
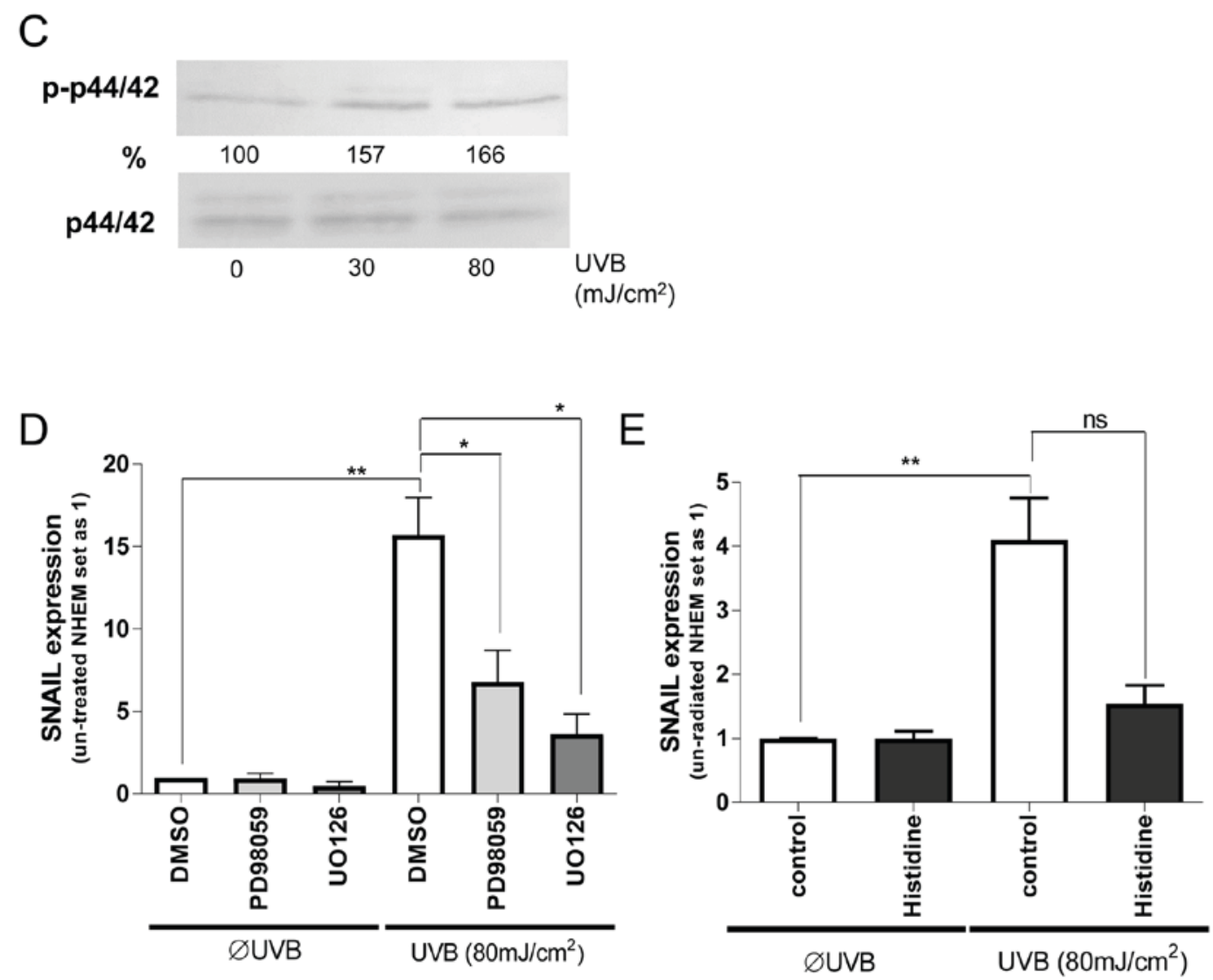

Figure 1. Effect of UVB radiation on SNAIL1 expression in NHEMs and melanoma Mel Ei cells. (A) Upregulation of SNAIL1 mRNA in NHEMs subsequent to exposure to different doses of UVB. (B) Upregulation of SNAIL1 mRNA in the melanoma Mel Ei cell line after exposure to UVB $\left(80 \mathrm{~mJ} / \mathrm{cm}^{2}\right)$ and completing the experiment at different time points. (C) Induction of ERK phosphorylation after different doses of UVB radiation in primary NHEMs. Densitometry prepared using ImageJ is shown in percentages. (D) Pre-treatment of NHEMs with the ERK inhibitors PD98059 or UO126 inhibits UVB radiation-induced SNAIL1 mRNA expression. Un-treated (ØUVB) control samples are presented next to the UVB $\left(80 \mathrm{~mJ} / \mathrm{cm}^{2}\right)$ treated samples. (E) Pre-treatment of NHEMs with the free radical scavenger histidine inhibits UVB $\left(80 \mathrm{~mJ} / \mathrm{cm}^{2}\right)$ radiation-induced SNAIL1 mRNA expression. Un-treated (ØUVB) control samples are presented next to the UVB $\left(80 \mathrm{~mJ} / \mathrm{cm}^{2}\right)$ treated samples. ${ }^{*} \mathrm{P}<0.05 ;{ }^{* *} \mathrm{P}<0.001 ;{ }^{* * *} \mathrm{P}<0.0001$. ns, not significant. UVB, ultraviolet B; SNAIL1, snail family transcriptional repressor 1; NHEMs, normal human epidermal melanocytes; ERK, extracellular signal-regulated kinase.

exposure were calculated by unpaired Student's t-test. All calculations were performed using the GraphPad Prism 7 software (GraphPad Software Inc., San Diego, CA, USA).

\section{Results}

ERK and SNAIL regulation by UVB irradiation in melanocytes. As the processes of proliferation and migration in melanocytes have a physiological as well as pathophysiological role, the present study determined whether there is an association between UVB radiation exposure and expression of ERK and SNAIL1 in melanocytes. It was identified that UVB-radiation induced SNAIL1 mRNA expression in a dose-dependent manner in NHEMs; the most effective dose was $80 \mathrm{~mJ} / \mathrm{cm}^{2}$ (Fig. 1A). This induction was also observed in the primary melanoma Mel Ei cells using the most effective 
A

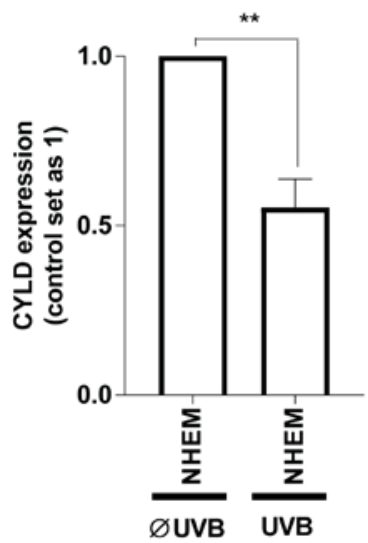

B

C

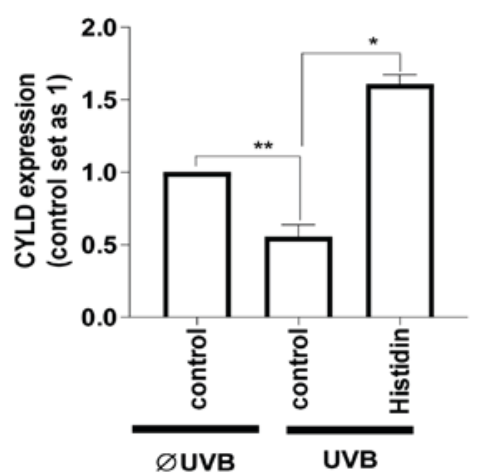

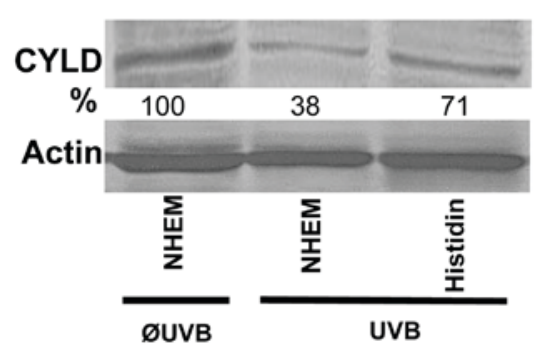

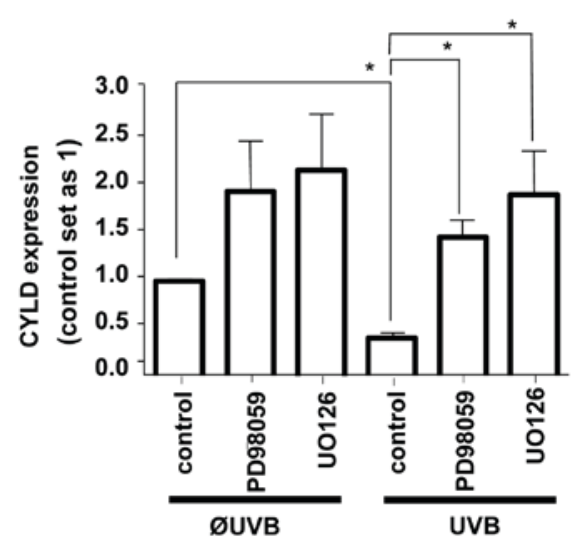

Figure 2. Effect of UVB radiation on CYLD expression in normal melanocytes. (A-C) Irradiation of NHEMs with UVB (80 mJ/cm $\left.{ }^{2}\right)$ led to downregulation of CYLD expression at the (A) mRNA and (B) protein levels compared to un-treated (ØUVB) control samples. Pre-treatment of NHEMs with the free radical scavenger histidine reversed the decrease of (B) CYLD protein and (C) mRNA expression after UVB $\left(80 \mathrm{~mJ} / \mathrm{cm}^{2}\right)$ radiation. Densitometry performed using ImageJ is shown as a percentage. (D) Pre-treatment of NHEMs with the extracellular signal-regulated kinase inhibitors PD98059 or UO126 reversed the decrease of CYLD mRNA expression after UVB radiation. ${ }^{*} \mathrm{P}<0.05 ;{ }^{* *} \mathrm{P}<0.001$. UVB, ultraviolet B; CYLD, CYLD lysine 63 deubiquitinase; NHEMs, normal human epidermal melanocytes.

UVB dose of $80 \mathrm{~mJ} / \mathrm{cm}^{2}$ (Fig. 1B). In the present study, it was further revealed that the maximum SNAIL1 mRNA level was reached after 180 min of UVB radiation, demonstrating a fast regulation of transcription.

To determine the mechanism of this UVB mediated SNAIL expression, ERK signaling was first concentrated on. Dose-dependent ERK activation by UV radiation in melanocytes was identified (Fig. 1C). Pretreatment of NHEMs with ERK-inhibitors (UO126 or PD98059) (Fig. 1D) significantly inhibited UVB induction of SNAIL1 expression, although the base level was not completely reached.

To determine the role of $\mathrm{UV}$-induced reactive oxygen species (ROS), NHEMs were pretreated with histidine (quencher to inhibit the formation of free radicals) prior to UV irradiation. Notably, histidine treatment almost completely inhibited UVB effects on SNAIL1 expression (Fig. 1E). This indicates that UVB can induce SNAILI expression in NHEMs via free radical-mediated ERK activation.

$C Y L D$ regulation by $U V B$ irradiation in melanocytes. Since SNAIL1 inhibited CYLD expression in melanoma cells (16), it was investigated whether the UVB-induced increase in SNAIL1 also affects CYLD levels in NHEMs or whether this is a cancer-specific regulation. Notably, UVB-radiation also led to the downregulation of CYLD mRNA (Fig. 2A) and protein (Fig. 2B) levels in NHEMs. Treatment with histidine (Fig. 2B and C) as well as with ERK-inhibitors (Fig. 2D) inhibited the UVB-induced downregulation of CYLD. These data indicate that UVB-induces ERK activation, and as a consequence, SNAIL1 expression led to the downregulation of CYLD in non-tumorous melanocytes similar, to the regulation found in malignant melanoma cells.

$N F-\kappa B$ involvement in the UVB dependent signaling cascade in melanocytes. As previous studies have suggested that SNAIL1 is a possible downstream target of NF- $\kappa \mathrm{B}(24)$, the present study further explored the role of this signaling pathway on SNAIL1 and CYLD expression in NHEMs and melanoma cells. Adenoviral transduction of a dominant nega-

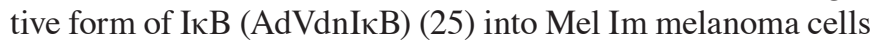
was performed, and the Mel Im cells were transiently transfected with a p65 (NF- $\kappa$ B subunit) expression plasmid. Neither SNAIL1 nor CYLD mRNA expression were significantly affected by p65 overexpression or AdVdnI $\kappa$ B (Fig. 3A and B). Expression of a dominant-negative form of $\mathrm{I} \kappa \mathrm{B}$ also failed to inhibit UVB-induced SNAILI expression in NHEMs 
A
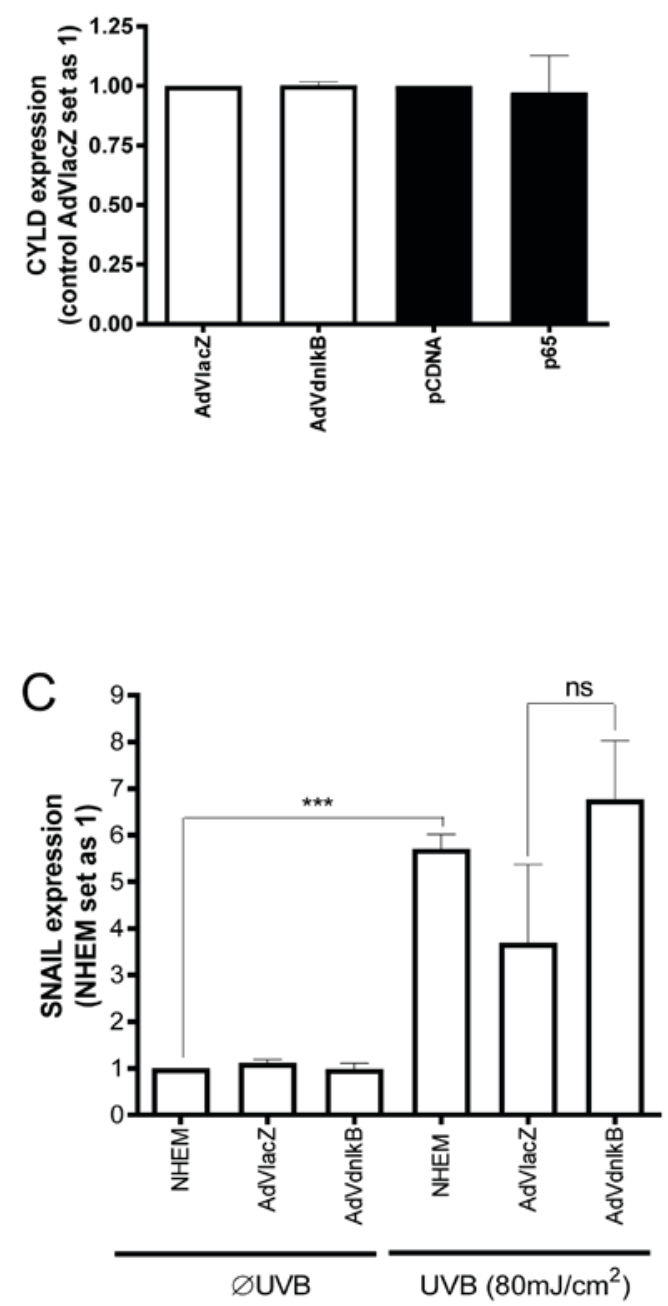

B
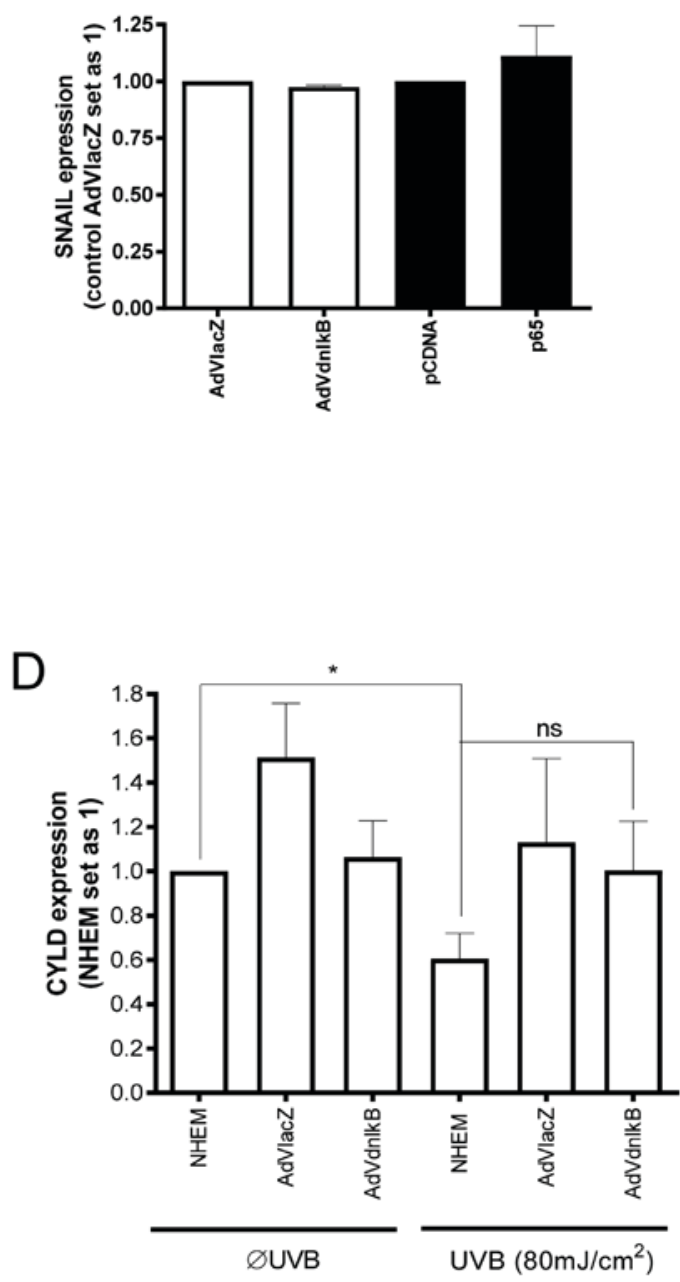

Figure 3. Analysis of the effect of nuclear factor- $\kappa$ B on the UVB-SNAIL1-CYLD signaling axis. (A) SNAIL1 and (B) CYLD mRNA expression in Mel Im cells

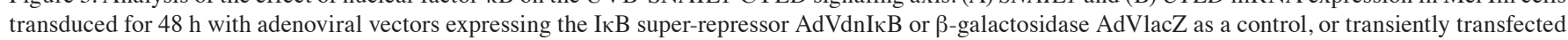
with p65 or the pcDNA3 control vector. The results of the groups were not significantly different. (C) SNAIL1 and (D) CYLD mRNA expression in NHEMs

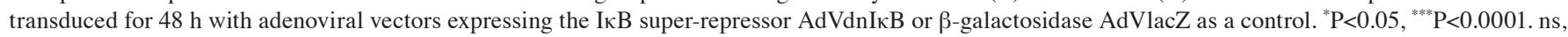
not significant. ØUVB, un-treated control samples.

(Fig. 3C). Furthermore, inhibition of the NF- $\kappa \mathrm{B}$ pathway did not significantly affect UV-mediated CYLD expression in NHEMs (Fig. 3D). Based on these data, it was concluded that UV-dependent downregulation of CYLD expression in NHEMs is not mediated by the NF- $\kappa$ B pathway, but rather by the ROS/ERK/SNAIL1 axis.

\section{Discussion}

UV-radiation is as an initiating factor in nevus formation. On the basis of the anatomical distribution of acquired nevi and a UV-associated mutation signature in the majority of the somatic mutations of nevi, it is hypothesized that UV radiation also contributes to melanoma initiation $(4,9)$.

When pigment cells undergo neoplastic transformation, these pathological derivatives are usually termed according to the pigment that characterized the original cell lineage, such as melanoma cells from melanocytes. Melanoma can arise spontaneously in a variety of animals, including dogs, horses, pigs and several fish. However, melanoma can also be induced by exposure to UV irradiation and carcinogens, or by the presence of relevant genetic changes in melanocytes (26). In previous years, varieties of genetic changes have been characterized in human melanocytic neoplasms and often correlate strongly with specific morphological characteristics (4). While progress has been made on defining the genetic changes present in melanoma, much remains to be learned about the specific characteristics of early malignant transformation of the melanocytes. As an example, approximately one-half of all melanomas in humans harbor oncogenic mutations in the $B R A F$ gene (e.g., V600E), which leads to constitutive activation of the RAS-RAF-MEK-ERK (p44/p42; MAPK) signaling pathway $(4,27)$. In contrast to melanoma cells, melanocytes exhibit low ERK-activity and the question of which early 
processes provoke pathological processes in melanocytes remains.

Epidemiological studies indicate the importance of UV radiation in the etiology of melanoma, and since $\mathrm{UV}$-associated mutations are relatively rare in melanoma, it was speculated that UV radiation may support melanoma development by indirect effects $(28,29)$. As a physiological response, melanocytes migrate to skin areas exposed to solar radiation, and start to proliferate and produce melanin, thereby exhibiting their protective effect against UV radiation (30). The signaling molecules involved in the stimulation of migration and proliferation of melanocytes following UV exposure remain unclear. However, the present study demonstrated that UVB radiation induces ERK-activity in melanocytes (NHEMs), similarly as previously shown in keratinocytes and melanoma cells $(31,32)$. Additionally, UVB radiation triggered ERK-mediated SNAIL1 induction and downregulation of $C Y L D$ expression in NHEMs. Following malignant transformation, constitutive high ERK activity and SNAIL1 expression allow melanoma cells permanently to exploit this mechanism to obtain a more aggressive phenotype $(16,17,23)$.

Previously, UVB light was identified as a trigger for direct association of CYLD with B-cell lymphoma-3 (BCL-3) (21). Following this association, CYLD removes lysine 63-linked polyubiquitin chains from BCL-3, which in turn prevents BCL-3 from translocating into the nucleus and further expressing different genes in keratinocytes (21). It was observed in malignant melanoma that loss of CYLD also induces nuclear accumulation of BCL-3 and NF- $\kappa \mathrm{B}$ activation, with the consequence of induced $\mathrm{N}$-cadherin (migration) and cyclin D1 (proliferation) activity (16). Data from embryogenesis and studies in Drosophila (24,33-35), suggesting that

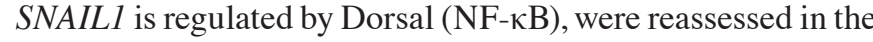
present study. However, it was found that in melanoma ERK signaling appears to be the major pathway responsible for the high constitutive activation of SNAIL1. While the migration and proliferation of melanocytes in response to UV are physiological with regards to skin protection by melanin, long-lasting UV radiation, which is considered as one of the main risk factors for the development of melanoma, may shift these cells towards malignant transformation. In normal epidermal melanocytes, UVB radiation induces ERK-activation and subsequently upregulates SNAIL1 expression. The repression of CYLD by SNAIL1 allows degeneration of melanocytes.

In melanoma cells, constitutively high ERK-activity (potentially caused by B-RAF mutations) leads to high SNAIL1 expression, which in turn causes a high and strong suppression of CYLD. Activation of cyclinD1 and N-cadherin leads to an increased proliferation rate of melanoma cells and contributes to the progression and metastasis of tumors.

\section{Acknowledgements}

The authors would like to thank the technicians Mrs. Lisa Ellmann (University Hospital, Regensburg, Germany) and Mrs. Nadja Schneider (Friedrich-Alexander University, Erlangen, Germany) for technical assistance. This study was supported by grants from the German Research Foundation to S.K., C.H. and A.B. within the research consortium (grant no. FOR2172).

\section{References}

1. Rowe CJ and Khosrotehrani K: Clinical and biological determinants of melanoma progression: Should all be considered for clinical management? Australas J Dermatol 57: 175-181, 2016.

2. Qadir MI: Skin cancer: Etiology and management. Pak J Pharm Sci 29: 999-1003, 2016.

3. Cui R, Widlund HR, Feige E, Lin JY, Wilensky DL, Igras VE, D'Orazio J, Fung CY, Schanbacher CF, Granter SR and Fisher DE: Central role of p53 in the suntan response and pathologic hyperpigmentation. Cell 128: 853-864, 2007.

4. Bastian BC: The molecular pathology of melanoma: An integrated taxonomy of melanocytic neoplasia. Annu Rev Pathol 9: 239-271, 2014.

5. Premi S, Wallisch S, Mano CM, Weiner AB, Bacchiocchi A, Wakamatsu K, Bechara EJ, Halaban R, Douki T and Brash DE: Photochemistry. Chemiexcitation of melanin derivatives induces DNA photoproducts long after UV exposure. Science 347: 842-847, 2015.

6. Nishisgori C: Current concept of photocarcinogenesis. Photochem Photobiol Sci 14: 1713-1721, 2015.

7. de Gruijl FR: Photocarcinogenesis: UVA vs UVB. Methods Enzymol 319: 359-366, 2000.

8. Tornaletti S and Pfeifer GP: UV damage and repair mechanisms in mammalian cells. Bioessays 18: 221-228, 1996.

9. Seebode C, Lehmann J and Emmert S: Photocarcinogenesis and Skin Cancer Prevention Strategies. Anticancer Res 36: 1371-1378, 2016.

10. De Fabo EC, Noonan FP, Fears T and Merlino G: Ultraviolet B but not ultraviolet A radiation initiates melanoma. Cancer Res 64: 6372-6376, 2004.

11. Noonan FP, Recio JA, Takayama H, Duray P, Anver MR, Rush WL, De Fabo EC and Merlino G: Neonatal sunburn and melanoma in mice. Nature 413: 271-272, 2001.

12. Halliday GM, Agar NS, Barnetson RS, Ananthaswamy HN and Jones AM: UV-A fingerprint mutations in human skin cancer. Photochem Photobiol 81: 3-8, 2005.

13. Gandini S, Sera F, Cattaruzza MS, Pasquini P, Picconi O, Boyle P and Melchi CF: Meta-analysis of risk factors for cutaneous melanoma: II. Sun exposure. Eur J Cancer 41: 45-60, 2005.

14. Bignell GR, Warren W, Seal S, Takahashi M, Rapley E, Barfoot R, Green H, Brown C, Biggs PJ, Lakhani SR, et al: Identification of the familial cylindromatosis tumour-suppressor gene. Nat Genet 25: 160-165, 2000.

15. Kuphal S, Shaw-Hallgren G, Eberl M, Karrer S, Aberger F, Bosserhoff AK and Massoumi R: GLI1-dependent transcriptional repression of CYLD in basal cell carcinoma. Oncogene 30: 4523-4530, 2011.

16. Massoumi R, Kuphal S, Hellerbrand C, Haas B, Wild P, Spruss T, Pfeifer A, Fässler R and Bosserhoff AK: Down-regulation of CYLD expression by Snail promotes tumor progression in malignant melanoma. J Exp Med 206: 221-232, 2009.

17. Kuphal S, Palm HG, Poser I and Bosserhoff AK: Snail-regulated genes in malignant melanoma. Melanoma Res 15: 305-313, 2005.

18. Ziegler-Heitbrock HW, Munker R, Johnson J, Petersmann I, Schmoeckel C and Riethmuller G: In vitro differentiation of human melanoma cells analyzed with monoclonal antibodies. Cancer Res 45: 1344-1350, 1985.

19. Tsuji T and Karasek M: A procedure for the isolation of primary cultures of melanocytes from newborn and adult human skin. J Invest Dermatol 81: 179-180, 1983.

20. Spangler B, Kappelmann M, Schittek B, Meierjohann S, Vardimon L, Bosserhoff AK and Kuphal S: ETS-1/RhoC signaling regulates the transcription factor C-Jun in melanoma. Int J Cancer 130: 2801-2811, 2012.

21. Massoumi R, Chmielarska K, Hennecke K, Pfeifer A and Fässler R: Cyld inhibits tumor cell proliferation by blocking Bcl-3-dependent NF-kappaB signaling. Cell 125: 665-677, 2006.

22. Jobin C, Hellerbrand C, Licato LL, Brenner DA and Sartor RB: Mediation by NF-kappa B of cytokine induced expression of intercellular adhesion molecule 1 (ICAM-1) in an intestinal epithelial cell line, a process blocked by proteasome inhibitors. Gut 42: 779-787, 1998.

23. Kuphal S, Poser I, Jobin C, Hellerbrand C and Bosserhoff AK: Loss of E-cadherin leads to upregulation of NFkappaB activity in malignant melanoma. Oncogene 23: 8509-8519, 2004. 
24. Barberà MJ, Puig I, Domínguez D, Julien-Grille S, Guaita-Esteruelas S, Peiró S, Baulida J, Francí C, Dedhar S, Larue L, et al: Regulation of Snail transcription during epithelial to mesenchymal transition of tumor cells. Oncogene 23: 7345-7354, 2004.

25. Hellerbrand C, Jobin C, Iimuro Y, Licato L, Sartor RB and Brenner DA: Inhibition of NFkappaB in activated rat hepatic stellate cells by proteasome inhibitors and an IkappaB super-repressor. Hepatology 27: 1285-1295, 1998.

26. Schartl M, Larue L, Goda M, Bosenberg MW, Hashimoto $\mathrm{H}$ and Kelsh RN: What is a vertebrate pigment cell? Pigment Cell Melanoma Res 29: 8-14, 2016.

27. Guadarrama-Orozco JA, Ortega-Gómez A, Ruiz-García EB Astudillo-de la Vega $H$, Meneses-García $A$ and Lopez-Camarillo C: Braf V600E mutation in melanoma: Translational current scenario. Clin Transl Oncol 18: 863-871, 2016.

28. Brenner M, Degitz K, Besch R and Berking C: Differential expression of melanoma-associated growth factors in keratinocytes and fibroblasts by ultraviolet A and ultraviolet $\mathrm{B}$ radiation. Br J Dermatol 153: 733-739, 2005.

29. Jhappan C, Noonan FP and Merlino G: Ultraviolet radiation and cutaneous malignant melanoma. Oncogene 22: 3099-3112, 2003.
30. Esparza-Soto M, Fox P and Westerhoff P: Transformation of molecular weight distributions of dissolved organic carbon and UV-absorbing compounds at full-scale wastewater-treatment plants. Water Environ Res 78: 253-262, 2006.

31. Pak BJ, Lee J, Thai BL, Fuchs SY, Shaked Y, Ronai Z, Kerbel RS and Ben-David Y: Radiation resistance of human melanoma analysed by retroviral insertional mutagenesis reveals a possible role for dopachrome tautomerase. Oncogene 23: 30-38, 2004

32. Peus D, Meves A, Vasa RA, Beyerle A, O'Brien T and Pittelkow MR: $\mathrm{H} 2 \mathrm{O} 2$ is required for UVB-induced EGF receptor and downstream signaling pathway activation. Free Radic Biol Med 27: 1197-1202, 1999.

33. Ip YT: Transcriptional regulation. Converting an activator into a repressor. Curr Biol 5: 1-3, 1995.

34. Ip YT, Park RE, Kosman D, Yazdanbakhsh K and Levine M: dorsal-twist interactions establish snail expression in the presumptive mesoderm of the Drosophila embryo. Genes Dev 6: $1518-1530,1992$

35. Marchal L, Foucaul A, Patissier G, Rosant JM and Legrand J: Influence of flow patterns on chromatographic efficiency in centrifugal partition chromatography. J Chromatogr A 869: 339-352, 2000. 